\title{
Risk assessment and evaluation: The implications of cracking for insurance cover and warranties
}

Received (in revised form): 24th January, 2005

John Parvin BSc (Hons), C Eng, MICE, MIStructE, ACILA

is a Chartered Civil/Structural Engineer as well as a Chartered Loss Adjuster. He had twenty-five years experience in the industry working with contractors and consulting engineers before joining Loss Adjusters Ellis and Buckle in 1992, where he assisted with the development of the project- managed subsidence Claims Manager for the Zurich Group, where he has responsibility for ensuring technical delivery of all aspects of subsidence claims handling. He is also the Chairman of the Subsidence Forum - an industry body created in March 2004.

\begin{abstract}
What are the risk assessments that are required in respect of the design, construction and performance of structures in particular the various site investigations? This can range from the desk study through to the actual physical site investigation and testing of the soil properties. In addition, there is the risk assessment of the quality and the processes used in the construction of the buildings and how these vary in relation to traditional methods and modern methods of construction. When the buildings are complete what are the measures that can be undertaken to minimist the risks of cracking occurring? These range from controlling the planting and maintenance of vegetation where the property is constructed on a clay soil, to ensuring that drains are kept watertight and suitable expansion joints are provided to allow for thermal movement.

In the unfortunate event that cracking does occur, what is covered under an insurance policy or building guarantee? The standard warranty consists of three parts: the building period; the developer's guarantee/warranty period (DGP/DWP) and the structural insurance period (SIP). Cover for cracking on insurance policies mainly relates to the peril of subsidence heave or landslip, although sometimes there will be cover under the accidental damage section of some policies.
\end{abstract}

\section{Keywords:}

risk assessment, masonry cracking, mitigatgion, tree management, modern methods of construction, subsidence cover

\section{INTRODUCTION}

The initial risk assessment starts with the site investigation, which is a term that encompasses many aspects affecting the design, construction 
History of site is important and performance of structures. In addition, there is a risk assessment of the quality and the processes used in the construction of the buildings and how these vary in relation to traditional methods and modern methods of construction. What are the mitigation measures that can be undertaken to minimise the risks of cracking occurring? In the unfortunate event that cracking does occur, what is covered under an insurance policy or building guarantee?

\section{RISK ASSESSMENTS}

How can the risk of cracking be reduced? Site investigations can include a wide range of activities such as:

- Desk studies

- Site visits

- Ground investigations

- Laboratory testing

- Geotechnical evaluation

- Site inspections.

The type of things necessary to be determined for the risk assessment include the following.

- Safe bearing capacity so that whole or differential settlement is avoided.

- The level at which foundations should be formed to prevent movement by heave, shrinkage etc

- The risk of general subsidence

- The effect of the proposed construction's overall stability

- The risks of excessive vibration from adjoining or nearby sites

- The effect of groundwater

- The effect of flooding

- Presence of existing substructure and services

- Contaminants

- Presence of vegetation.

\section{Desk-top assessment}

In the first instance, the desk-top assessment involves an examination of geological and topographical maps, together with aerial photographs. Occasionally, the use of photographs will help to identify where trees have been removed. This is particularly important if the land has changed hands several times in recent years and the full history is unknown. On clay soils heave can occur $10-15$ years later.

It is possible that a pre-existing landslip is present. Any slope greater than 8 degrees is a potential risk and this may be picked up from a combination of a walkover survey and an examination of maps. Other sources of information are the local authority, local builders, public utilities, libraries and local archives. Building Research Establishment (BRE) Digest 318 'Site Investigations for Low Rise Buildings' and BRE Digest 348 'Site Investigations for Low Rise Buildings — The Walkover Survey’ provide more guidance. 


\section{Desk studies should not be underestimated}

Other questions to be asked at this stage include the following. Has the assessment of the site taken into account the site history? Is there a known subsidence history? Is the site underlain by a known strata which may contain natural cavities or be liable to subsidence due to adverse foundation conditions? Has there been any previous development such as mining or other industrial developments? Have any reports from nearby sites been consulted? Is there any made ground on or near the site? Is it a marginal site with the presence of poor ground at depth, ie peat? What if there is the risk that a raft will tilt or settle beyond acceptable tolerances?

Within the Zurich Building Guarantee Manual, minimum guidance is provided for the design of the foundations which essentially makes reference to the Approved Document A - Structure (England and Wales), The Northern Ireland Building Regulations and Technical Standards Part C - Structure (Scotland). Reference is also made to current British standards including BS8004, 'Code of Practice for Foundations' and BS8103, 'Structural Design of Low Rise Buildings'.

If there are trees present, what assessments need to be made to undertake the appropriate design and assessment? Zurich and the National House Building Council (NHBC) provide guidance on building distances from trees and the depths of proposed foundations. This guidance also relates to the classification of the soil as high, medium or low clay and hence its potential for shrinkage, the potential water demand for the trees in question, their potential mature height, their distance from the foundations and, finally, geographical factors such as whether the site is in the South-East of England or Scotland. The effect of heave on the building has to be considered and the necessary steps taken to minimise these effects. In the majority of cases, if trees are removed from outside the footprint of the building then compressible boards may be required on the inside face only. If trees are removed over the whole area then precautions are required on both faces.

If construction is taking place on sloping ground or there are groups of trees then adjustments need to be made to the foundation depth to take account of the vegetation. If there are non-shrinkable soils over shrinkable clays then, again, a detailed assessment of foundation depth is required. With increasingly more construction taking place on brownfield sites and sites with poor bearing capacity it is even more important that the relevant assessments are made.

Many of the activities carried out as part of the investigations are common sense. The problems come in finding the various documents. Without some background knowledge, however, it is not possible to plan for trial pitting and boreholes, and hidden dangers at depth or on parts of the site would not be discovered. For example, a conservative design could be used to introduce wider footings to avoid foundation-bearing failure; however, this would not prevent heave if the width of the foundation was only increased and no account of depth or anti-heave was included in the design.

Experience has shown that desk studies give much better value for money than activities such as trial pits and deep boreholes. When soil 
information is available, however, the plasticity of the clay should be identified as the degree of desiccation will help to make the correct decision in respect of the foundation design.

\section{STRUCTURE AND FOUNDATION DESIGN}

For most types of subsidence it may be possible to design suitable foundations to cope with the movement expected. The risk of foundation movement needs to be reconsidered with appropriate inspections at the key construction phases. Therefore, it will depend on the site and the competency of the developer/builder as to how many inspections are undertaken at the time of construction of the foundations. For example, evidence of fill material or the presence of roots may result in the redesign of the foundations at this stage. The design of structures can also resist subsidence movements; timber-framed structures are more inherently flexible than masonry.

\section{Modern methods of construction (MMC)}

What are the risks involved with traditional methods of construction such as brick block walls compared with MMC? The majority of homes in the UK are still constructed using traditional 'brick and block' masonry. Within the last few years, however, there has been increased use of MMC for housing, driven by a range of factors including demands for faster construction and skills shortages. There is uncertainty about the exact amount of MMC housing.

Typically, MMC involves the manufacture of house parts off-site in a specially designed factory. The two main products of MMC are:

- Panels: including ready-made walls, floors and roofs. These are transported to the site and assembled quickly, often within a day. Some panels have wiring and plumbing already inside them, making construction even faster.

- Modules: ready-made rooms, which can be pieced together to make a whole house or flat but are used most frequently for bathrooms or kitchens, where all the fittings are added in the factory. Also known as 'pods', modules can include volumetric units, which are either part or whole structures.

The benefits of MMC are unproven
MMC can also include innovative site-based methods, such as use of concrete moulds. A range of materials is used, the most common being wood, steel and concrete, although many houses built in the UK using MMC have a brick outer layer and so look like traditional houses. Many of the benefits of using MMC for housing are as yet unproven or contentious, however, government and manufacturers suggest the main advantages are the following.

- Economic: MMC houses typically have fewer defects and can be built more quickly.

- Environmental: the houses can be more energy efficient, may involve less transport of materials and produce less waste. 


\section{More site inspection required with traditional construction}

- Social: there may be fewer accidents and less impact on local residents during construction.

There is uncertainty about the level of skills needed for MMC compared with masonry construction. MMC can require highly skilled labour for precise on-site assembly of factory-made house parts. Some of the problems with prefabricated housing built during the 20th century stemmed from poor skills, rather than defects with the housing materials. The Construction Industry Training Board (known as CITB Construction Skills), funded by the industry and government, is developing MMC training courses for the estimated 2,000 workers currently erecting MMC housing with no formal qualifications. There are currently over 30 housebuilding factories in the UK, while a recent survey found industry capacity to produce over 30,000 MMC homes per year.

The number of defects in traditionally built homes in the UK is considerable, with house builders allocating up to $£ 2,000$ per house to rectify problems. Greater use of factory production can reduce defects because there is less risk of weather damage during construction, and materials can be standardised and tested more easily. But if problems are found belatedly with a particular MMC then this would have been replicated in many homes, because they are mass-produced. Housing is built to last a minimum of 60 years, so problems could go unnoticed for some time. For this reason, building insurers, mortgage lenders and surveyors are cautious about greater use of MMC. For example, some insurers are worried about the resilience of MMC to flooding. In contrast, the risks of traditional site-based masonry construction are well known because the method has been used for a long time. Accreditation systems to test the performance of housing products are operated by the British Board of Agrément and BRE certification, but the process can take over a year and cost up to $£ 100,000$, meaning that not all companies apply. If houses are built using unaccredited methods then it can be difficult to gain buildings insurance.

Because most UK MMC developments are made to look like traditional brick houses, potential occupants may be unaware of the construction method used. The planning system has an important indirect influence on the MMC market because of its role in determining the supply of homes.

As part of the risk assessment for MMC housing, there is the need to move the emphasis on site visits to the factory to ensure inspections are made at key stages. It is important that each factory also operates an approved quality control process. With traditional methods, as far as cracking is concerned, there is more likelihood of cracking occurring as a result of drying shrinkage due to the volumes of water used in the process.

For traditional construction there will be a need to undertake more inspections at key stages of the construction. If it is a scheme which is to be warranted, for example, with a Zurich Building Guarantee, then the warranty provider (Zurich) will work with the developer.

In this example, there will be a tightly targeted programme of risk management using Zurich's own surveyors. They will assess each development on its merits, depending on its environment, the type of 
construction being adopted and the capabilities and expertise of the builder. Risks can never be eliminated fully but the programme of key stage inspections will serve to:

- Reduce the uncertainties on difficult sites

- Minimise the risk of defects going unnoticed

- Help reduce claims.

Whether traditional build or MMC, the main risk, as far as cracking is concerned, probably still relates to the design and installation of the foundations.

\section{MITIGATION}

Guidance on drying-out new properties

\section{Tree removal and planting regimes}

The overall planting regime of a site needs to be considered to ensure the correct foundation depths are used. As well as the overall site-planting scheme, individual homeowners are provided with guidance on tree planting and removal. For many homeowners, one of the pleasures is planting trees or shrubs and this equally applies to new build and existing houses. It is important that, depending on the soil type, professional advice is taken to determine the extent of any planting regime. Similarly, professional advice should be taken before the removal or cutting back of trees, particularly in a conservation area or where the tree is subject to a tree preservation order.

Notwithstanding the above, many properties are affected by subsidence as a result of clay shrinkage exacerbated by the effects of vegetation. There is much work that has been carried out on the water demand of trees and how they cause subsidence damage to domestic properties. If the owner makes a claim, the matter is investigated by the insurer who, in many instances, will ask for the advice of an arboriculturist on the amount of tree management that is required. In the early 1990s, some vegetation was only thinned out and not many trees were removed. If increasingly more of the evidence implicates a tree and there is not a substantial risk of heave, then it is considered appropriate to remove the tree. It may be possible to replace it with a less water demanding species situated further away from the property. In most instances, the insurance company pays for this replacement as part of the remedial work.

\section{What mitigation can be undertaken to help prevent cracks?}

If the problem relates to damaged drains, which have softened or washed away the fines in the subsoil, then the drains need to be repaired or replaced to allow the ground to return to its former condition.

If the damage is as a result of drying shrinkage then Zurich provides guidance to homeowners on drying out the structure. In traditional methods of construction there are several thousand litres of water used. It is important therefore to provide adequate ventilation to prevent shrinkage cracking. 
If there is likely to be thermal movement, movement joints should be introduced to accommodate the movement and prevent the cracking.

\section{WARRANTY/GUARANTEE}

So what do homeowners do if they discover cracks? Do they claim on the warranty if it is a new build or a conversion or will their household insurance policy deal with the matter?

\section{What exactly is a warranty?}

A warranty is an insurance policy that is taken out to cover against latent defects causing physical damage in the construction of a new home. It provides cover both on conversions and new builds. Full cover is not in place until the insurance certificate is issued. As with any insurance policy, the Zurich '10' policy needs to be read in accordance with the policy schedule.

The standard warranty consists of three parts:

- The building period: this is protection against the loss of the deposit in situations where the developer goes bankrupt etc.

- Developer's Guarantee/Warranty Period (DGP/DWP) which is usually two years for new builds and one year for conversions.

- The Structural Insurance Period (SIP) is the remaining period of the policy cover.

The insurance company only steps in during the DWP if the developer fails to meet their obligations under the policy.

During the period from two to ten years after commencement of the policy, Zurich or the NHBC will deal with damage that is a result of a latent defect. As far as the policy is concerned, this means major damage and typically will include:

- Damage including ground movement affecting the structural stability of the new home caused by a defect;

- Rising dampness or damp penetration into the interior of the new home, except through windows, doors and frames, caused by a defect;

- Debonding of external render which allows moisture to penetrate into the structure and/or debonding of the internal plaster caused by a defect;

- Cracking in the new home that is classified as severe according to BRE Digest 251.

\section{Most significant cracking is caused by foundation movement}

As far as cracking is concerned, the most significant relates to foundation movement. If a claim is made for this, then the matter is investigated by the insurer.

The cover under the policy is normally limited to the main dwelling and cracking of external walls and paths is unlikely to be covered unless there is an endorsement on the policy. There is also cover for alternative accommodation, which is subject to a limit. In addition, there will be a limit on the policy relating to professional fees. If the damage is covered by any other policy then the warranty does not apply. 


\section{Thermal cracking is not usually covered by insurers}

\section{SO WHAT DOES AN INSURANCE POLICY COVER?}

Most domestic policies are written on a peril basis where they outline a number of perils. The most significant peril that covers cracking to buildings is the subsidence peril. This section will normally include subsidence or heave of the site and/or landslide. Other potential perils, which might provide cover for cracking, are escape of water, earthquake, impact or storm. If the policy has accidental damage cover then this section could be brought into play.

Risk-averse surveyors may not have helped the high numbers of subsidence notifications, and neither have mortgage companies which increasingly make more simplistic valuation surveys available to purchasers. In fact, more than half of the potential subsidence claims notified turn out to be some other cause. As Figure 1 shows, in recent years there have been around 35,000 subsidence notifications, a figure which rose to 54,000 in 2003 (many people considered 2003 to be an event year).

So how can one tell whether distressed decor is subsidence or settlement, thermal movement or brickwork shrinkage? Normally the householder should contact their insurer and they will make an assessment based on the information supplied and whether the potential cover is in place, then the insurer will appoint a loss adjuster or utilise their own field staff who are normally chartered engineers or surveyors.

Poor building practice can result in damage that looks like subsidence. For example, experienced builders have been called to new developments where sodden bricks, left uncovered, have dried too quickly in hot weather and created a large crack at the point of least resistance above a window frame.

While old buildings have shallower foundations, they are constructed with more pliable lime mortar, allowing for thermal movement as the building expands and contracts with the seasons. Not only do new builds use more brittle cement mortar, but also they are generally more rigid and angular to help hold in the heat. Although houses need to hold the heat, it does increase the difference in temperature between the outside and inside and therefore increases the risk of cracking due to thermal movement. This is a common cause of innocuous cracking in new builds

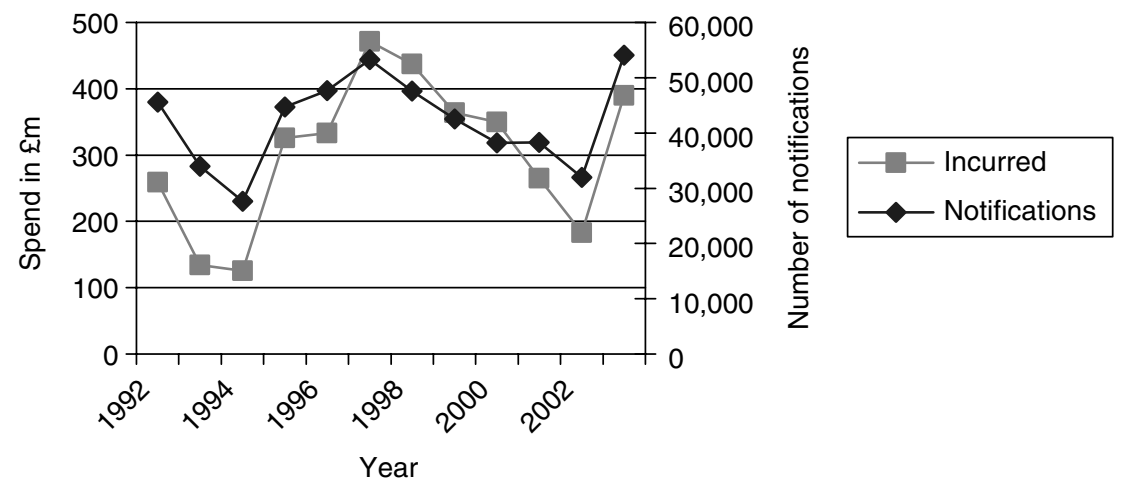

Figure 1: $A B I$ subsidence figures (figures are claims details submitted by member companies on a quarterly basis) 
when, for example, plaster can shrink away from door and window frames. A recent Association of British Insurers' (ABI) report on the subject said: 'A tendency towards cyclical weather behaviour — dry, wet, dry, wet - will exacerbate cracks caused by thermal movement, especially in the frame of the house.' This type of defect is not covered by the insurance policy.

Settlement is what happens initially when the building beds down. In the absence of specific definitions within the policy or specific exclusions, however, the insurance industry does not normally distinguish between subsidence and settlement. Out of the claims diagnosed as subsidence, only around one-third relate to clay shrinkage in a non-event year, while this can go up to 70 per cent in an event year such as 2003.

The other main cause of subsidence is the escape of water from drains where water leaking into the ground can soften it and wash away soil, especially in areas with a high sand or gravel content.

If the insurer is able to determine that subsidence has occurred then most policies will have a number of exclusions under the peril. These will relate to the following:

- coastal and river erosion;

- damage to floor slabs unless the foundations to the load-bearing walls are damaged at the same time;

- damage to external features such as walls, paths etc, unless there is damage to the main dwelling at the same time and by the same cause;

- faulty design, faulty workmanship or demolition;

- policy excess.

In the warranty period of a new build the claim will be dealt with under that policy if the design or workmanship were faulty. If a potential claim exists then site investigations are usually undertaken which will normally involve trial holes and hand augers and will follow the same principles as those outlined for a new build.

If a valid claim is identified and accepted then the normal process is to undertake mitigation involving tree management or drain repairs. There may be a short period of monitoring. In the past, the monitoring was very often around 12 months, but in many instances now this can be reduced. Figure 2 presents a summary of the process involved from claim notification through to a finalised claim.

The adjusters produce a scheme of repairs, which very often will include the strengthening of the masonry with the introduction of reinforcement. On completion of the repairs a certificate of structural adequacy is normally produced. For domestic policies, most insurers will provide continuing cover for a prospective purchaser.

There is no cover for underpinning as a right under the policy and each case has to be looked at on its merits.

If there is a dispute there are many guidelines on how to handle claims. The matter is referred to the chief executive of the insurance company and, following a financial decision, it can be referred to the Financial Ombudsman service. 


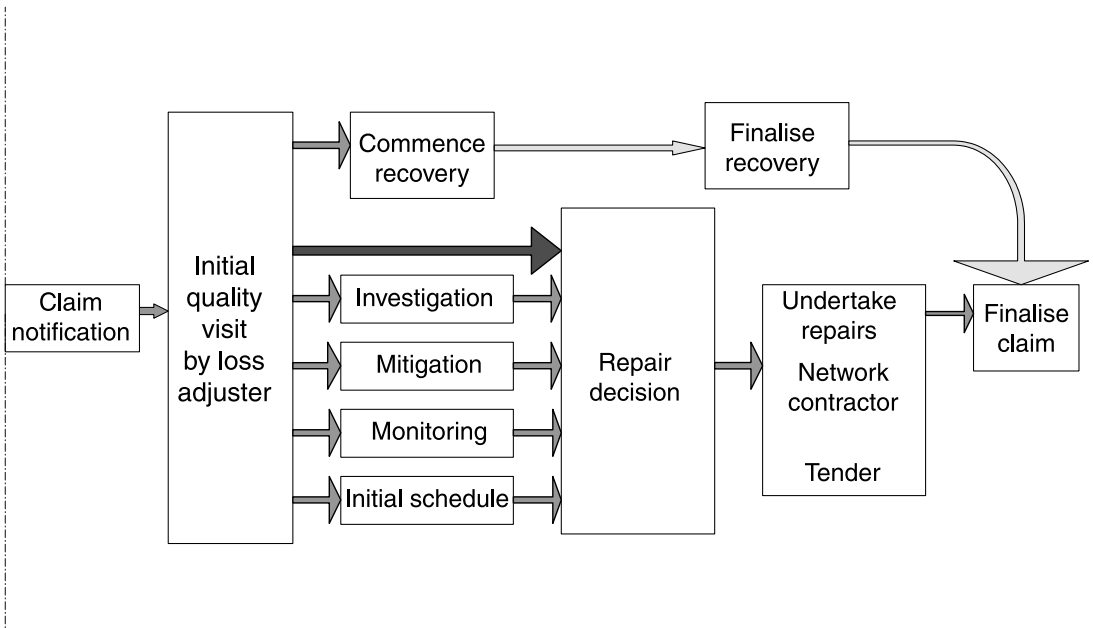

Figure 2: The process

\section{Subsidence forum created in 2004}

\section{More attention to risk required}

The Association of Underpinning Contractors (ASUC) called for the creation of a subsidence forum to achieve best practice in respect of claims handling. This forum was established in May 2004 with members from all areas of the industry working together to achieve this goal. Further details can be found on their website: www.subsidenceforum.org.uk. On those occasions when underpinning is considered necessary it is preferable to use companies which are members of the ASUC or others which can provide an insurance-backed guarantee.

For the future, should more risk assessments be undertaken, drains repaired and tree management conducted on a more regular basis prior to a claim being submitted? There are many companies using existing data to try and predict whether trees are impacted and what management is required. As far as other perils and cover are concerned under insurance policies, there are claims submitted for minor earthquake damage, impact from motor vehicles, which is self-explanatory, as is vibration from construction activities such as piling. In the majority of instances there will be cover for the earthquake and impact damage but, depending on the type of policy, vibration damage may not be covered. Other causes which are unlikely to be covered by a policy are lintel failure, corroded wall ties, roof spread and thermal movement.

\section{CONCLUSION}

In summary, in order to minimise cracking the right level of site investigation needs to be carried out when building new properties, together with the right level of management and inspection at the relevant stages to minimise the risk. If cracking has occurred and it is considered to be related to an insurance peril then the insurance company should be notified as soon as possible. It will investigate and, subject to the peril being covered by the relevant policy conditions, it will arrange the repairs. 


\section{References}

Building Research Establishment (1995) Site Investigations for Low Rise Buildings, Digest 318, BRE, 1st October.

Building Research Establishment (1989) Site Investigations for Low Rise Buildings - The Walkover Survey, Digest 348, BRE, 1st December.

Building Research Establishment (1995), Driscoll, R. Assessment of Damage in Low Rise Buildings, with particular reference to progressive foundation movement, Digest 251, BRE, 1st January.

Parliamentary Office of Science and Technology - Postnote (2003), Number 209, 1st December.

Zurich Building Solid Foundation Manual available from the Zurich Building Guarantee Technical Department. Originally titled Zurich Building Guarantee Manual.

\section{Note}

The British Board of Agrément is an organisation partnered with the government and whose governing body includes representation from the Office of the Deputy Prime Minister. It has been in existence for over 35 years and provides independent tests on the performance of building products. 